\title{
Relation between pelvic floor neurophysiological abnormalities and erectile dysfunction in patients with obstructed defecation
}

\author{
Mervat Sheta Elsawy and Emmanuel Kamal Aziz Saba* (i)
}

\begin{abstract}
Background: Obstructed defecation is a common pelvic floor medical problem among adult population. Pelvic floor disorders were reported to be associated with sexual dysfunction including erectile dysfunction among male patients. The aim was to determine the relation between pelvic floor neurophysiological abnormalities and erectile dysfunction in male patients with obstructed defecation.

Methods: This cross-sectional study included 65 married male patients with obstructed defecation and a control group consisted of 15 apparently healthy married males. Assessment of obstructed defecation severity was done by using modified obstructed defecation score, time of toileting and Patient Assessment of Constipation-Quality of Life questionnaire. Assessment of erectile functions was done using erectile function domain of International Index of Erectile Function questionnaire and Erectile Dysfunction-Effect on Quality of Life Questionnaire. Anal manometry and dynamic pelvis magnetic resonance imaging were done. Electrophysiological studies included pudendal nerve motor conduction study and needle electromyography of external anal sphincter, puborectalis and bulbocavernosus muscles.
\end{abstract}

Results: There were 32 patients (49.2\%) who had erectile dysfunction. The maximum straining anal pressure was significantly higher among patients with erectile dysfunction. Pudendal nerve terminal motor latency was significantly delayed and the percentage of bilateral pudendal neuropathy was significantly higher among patients with erectile dysfunction. The percentage of electromyography evidence of denervation with chronic reinnervation in the external anal sphincter and bulbocavernosus muscles were significantly higher among patients with erectile dysfunction. Regression analysis detected three co-variables to be associated with significantly increasing the likelihood of development of erectile dysfunction. These were maximum straining anal pressure (odd ratio $=1.122$ ), right pudendal nerve terminal motor latency (odd ratio $=3.755$ ) and left pudendal nerve terminal motor latency (odd ratio $=3.770$ ).

Conclusions: Erectile dysfunction is prevalent among patients with obstructed defecation. It is associated with characteristic pelvic floor electrophysiological abnormalities. Pelvic floor neurophysiological changes vary from minimal to severe neuromuscular abnormalities that usually accompanying erectile dysfunction. Pudendal neuropathy and increased maximum straining anal pressure are essential risk factors for increasing the likelihood of development of erectile dysfunction in patients with obstructed defecation.

\footnotetext{
*Correspondence: emadaziz55@yahoo.com

Physical Medicine, Rheumatology and Rehabilitation Department, Faculty

of Medicine, Alexandria University, Alexandria, Alexandria Governorate

21131, Egypt
}

(c) The Author(s) 2021. Open Access This article is licensed under a Creative Commons Attribution 4.0 International License, which permits use, sharing, adaptation, distribution and reproduction in any medium or format, as long as you give appropriate credit to the original author(s) and the source, provide a link to the Creative Commons licence, and indicate if changes were made. The images or other third party material in this article are included in the article's Creative Commons licence, unless indicated otherwise in a credit line to the material. If material is not included in the article's Creative Commons licence and your intended use is not permitted by statutory regulation or exceeds the permitted use, you will need to obtain permission directly from the copyright holder. To view a copy of this licence, visit http://creativecommons.org/licenses/by/4.0/. 
Keywords: Bulbocavernosus muscle, Erectile dysfunction, Functional obstructed defecation, Obstructed defecation, Pelvic floor muscles, Pudendal nerve motor conduction study, Sexual dysfunction

\section{Background}

Obstructed defecation (OD) is a prevalent problem. Its prevalence is about $7 \%$ of the adult population $[1,2]$. It has two different pathophysiological mechanisms. Functional OD is anismus which is due to a functional abnormality. Mechanical OD is due to anatomical lesions as rectocele and rectal intussusception [3, 4]. OD affects and impairs health-related quality of life to a great extent $[5,6]$.

Sexual health is an essential part in the health-related quality of life [7-10]. Pelvic floor disorders including OD were reported to be associated with sexual dysfunction [11]. Male patients with OD may suffer from sexual dysfunctions and sexual life impairments. Sexual dysfunction as erectile dysfunction (ED) is present among patients suffering from OD, and questionnaires are useful in assessment of these patients $[9,12]$.

However, among OD patients, the evaluation of the anorectal function and the anatomical defects often receive more attention than the sexual function [11]. OD is usually associated with electrophysiological changes in the pelvic floor muscles and nerves. These include pudendal neuropathy and neuropathic abnormalities in the external anal sphincter (EAS) and puborectalis (PR) muscles, as well as other pelvic floor muscles as bulbocavernosus (BC) muscle. These changes vary in severity among different patients according to the severity of OD [13, 14]. These neurological changes could have a role in the impairment of the sexual functions among male patients with OD $[15,16]$. ED could be as a result of neurological abnormalities in the pelvic floor nerves and muscles $[7,9,12,17]$.

To the best of the authors' knowledge, there is no previous research that discussed the relationship between different pelvic floor electrophysiological changes and ED among patients with OD. The knowledge of this could help in the explanation of the improvement of the erectile sexual dysfunctions after pelvic floor rehabilitation with biofeedback therapy [18]. The aim of the work was to determine the relation between pelvic floor neurophysiological abnormalities and ED in male patients with OD.

\section{Methods}

Sixty-five married male patients with OD were included in this cross-sectional study. All of them were recruited randomly from those who attended the Pelvic Floor Rehabilitation clinic. It included a control group of 15 apparently healthy married male volunteers.
Figure 1 illustrates the inclusion criteria which is the clinical diagnosis of OD (Rome III criteria for OD) [3, 19]. The two different forms of OD were included in the study whether functional OD as anismus or mechanical OD due to anatomical lesions as rectocele, as well as the combination of both conditions together (mixed form of OD) $[3,4]$. The patients were divided into two groups depending on the presence of ED. It is defined as the inability of achievement and maintenance of adequate penile erection which is sufficient to allow a satisfactory sexual performance. Patients were classified as having ED when they complained of ED and the score of erectile function domain of International Index of Erectile Function (IIEF) questionnaire was less than 26 [20]. Figure 1 illustrates the exclusion criteria of the study $[6,14,21]$. The researchers explained the work to the participants who gave an informed consent. Institutional Ethics Committee accepted the study.

All patients were assessed as the following: demographic parameters collection, history taking and measurements of body mass index (BMI) [22]. Assessment of OD severity was done by using modified OD score (MODS) and time of toileting [6, 23]. MODS represents the sum of individual scores for 7 symptoms and one score for life style alteration. Its total score ranges between zero (best) to 24 (severest form) [23]. The patient's quality of life was graded using the Patient Assessment of Constipation-Quality of Life questionnaire (PAC-QoL) [23]. It assesses physical discomfort, psychosocial discomfort, worries and concerns, and dissatisfaction. PAC-QoL score consists of 28 questions scored from zero to four with a total score ranges between zero (best) to 112 (worst) [23].

Assessment of the erectile functions of the patient was done using erectile function domain of IIEF questionnaire (Fig. 2) [20]. Assessment of the effect of ED on the patient's QoL was done using the Erectile Dysfunction-Effect on Quality of Life (ED-EQoL) questionnaire (Fig. 2) [10].

Clinical evaluation included perineal, anorectal and neurological examination [24]. Pelvic floor muscle strength was graded using Modified Oxford Scale (MOS) $[25,26]$. The muscle strength was quantified from zero (absence of muscle contraction) to five (a completely normal muscle strength) [26].

Anal manometry assessment was performed using the manometric biofeedback device (Myomed 632-equipment, Enraf Nonius, The Netherlands). It included 


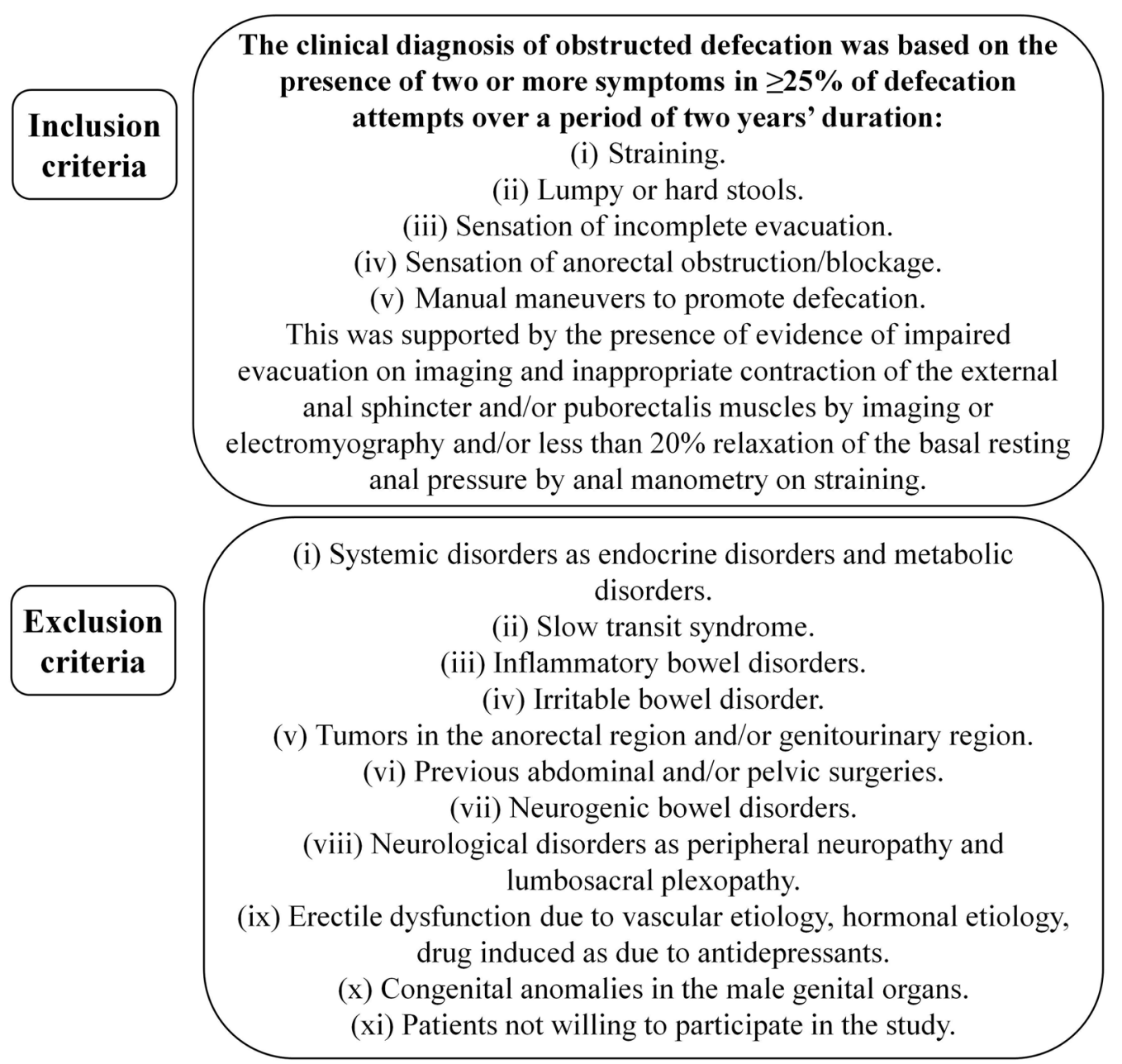

Fig. 1 Inclusion and exclusion criteria of the research $[3,6,14,19,21]$

assessment of maximum squeezing anal pressure and maximum anal pressure during straining to evacuate [1, 27].

Dynamic pelvis magnetic resonance imaging (MRI) was done for all patients for proper diagnosis of the etiology of OD $[28,29]$. It was done using a 1.5 Tesla closed-configuration Phillips Gyroscan System using a body-array-surface coil [29].

Pelvic floor electrophysiological studies were conducted on a Nihon Kohden Neuropack MEB-7102 mobile machine (with two channels) (Nihon Kohden Corp., Japan). Pudendal nerve terminal motor latency (PNTML) was assessed using pudendal nerve motor conduction study. Needle electromyography (EMG) for EAS, $\mathrm{PR}$ and $\mathrm{BC}$ muscles was done [30, 31].

Data were analyzed using Statistical Package of Social Science (version 17) software. Analytic measures included the following: (i) qualitative data were analyzed using Chi-square test or Fisher's exact test (when required); (ii) quantitative data were analyzed using Mann-Whitney test and Kruskal-Wallis test; and (iii) correlation was done using Spearman's correlation test. A binary logistic regression analysis was used to detect the impact of some selected co-variables on the development of ED. The results were expressed as odd ratio (OR) and 95\% confidence interval. Goodness of fit of binary logistic regression analysis was evaluated using the Hosmer and Lemeshow test. Difference was interpreted as significance when $P$ value was $<0.05$.

\section{Results}

There were 65 male patients with OD included in the study. Their mean age was $42.93 \pm 10.33$ years (range 22 to 65 years). The control group consisted of 15 apparently healthy males, and their mean age was $42.80 \pm 13.83$ years (range 21 to 63 years). No significant difference was found between both groups regarding age $(Z=-0.056$, $P=0.956)$. 


\section{Erectile function domain of International Index of Erectile Function questionnaire}

This questionnaire consists of 6 questions scored from 0 to 5 with a total score of 0 (the poorest erectile function) to 30 (the best erectile function).

Patients with an erectile function domain of International Index of Erectile Function score less than 26 were considered to have erectile dysfunction.

The score interpretation was as the following:

No erectile dysfunction : a score of 26-30.

Mild erectile dysfunction : a score of 22-25.

Mild to moderate erectile dysfunction : a score of 17-21.

Moderate erectile dysfunction : a score of 11-16.

Severe erectile dysfunction : a score of 6-10.

Erectile Dysfunction-Effect on Quality of Life questionnaire

This questionnaire consists of 15 questions scored from 0 to 4 with a total score of 0 (the best quality of life) to 60 (the poorest quality of life).

The score interpretation was as the following:

Mildly affected quality of life: a score of $<15$.

Moderately affected quality of life: a score of 15-29.

Severely affected quality of life: a score of $\geq 30$.

Fig. 2 Illustration of the erectile function domain of International Index of Erectile Function questionnaire and the Erectile Dysfunction-Effect on Quality of Life questionnaire and their interpretation $[10,20]$

The patients were divided according to the presence of ED into two groups depending on the results of patients' complaint and erectile function domain of IIEF score. Patients with ED group consisted of 32 (49.2\%) patients, and patients without ED group consisted of 33 (50.8\%) patients. The clinical characteristics of the two patient groups and control group are tabulated in Table 1 . There were no statistically significant differences between the two patient groups regarding the duration of OD symptoms, MOS, etiology and type of OD.

The results of anal manometric assessment are tabulated in Table 2. All patients had manometric evidence of failure of relaxation of the pelvic floor muscles during attempts at defecation. There were statistically significant differences between the two patient groups versus the control group regarding the maximum squeezing anal pressure and the maximum straining anal pressure
(Table 2). The maximum straining anal pressure was statistically significantly higher among the OD with ED group in comparison to the OD without ED group (Table 2).

Results of electrophysiological assessment are tabulated in Table 3. The PNTML was significantly delayed in the OD with ED group in comparison to the control group, as well as OD without ED group (Table 3 ). The percentage of bilateral pudendal neuropathy was significantly higher among OD with ED group versus the other patient group (Table 3). The percentage of EMG evidence of denervation with chronic reinnervation (i.e., neuropathic abnormalities) in the EAS and $\mathrm{BC}$ muscles were significantly higher among OD with ED group (Table 3).

Correlation between erectile function domain of IIEF questionnaire and ED-EQoL questionnaire with different clinical, anal manometric and electrophysiological 
Table 1 Clinical characteristics of the two patient groups and control group

\begin{tabular}{|c|c|c|c|c|c|}
\hline Clinical characteristics & $\begin{array}{l}\text { OD with ED group } \\
\text { ( } n=32 \text { patients) } \\
\text { mean } \pm S D\end{array}$ & $\begin{array}{l}\text { OD without ED group } \\
\text { ( } n=33 \text { patients) } \\
\text { mean } \pm S D\end{array}$ & $\begin{array}{l}\text { Control group } \\
\text { ( } n=15 \text { subjects) } \\
\text { mean } \pm S D\end{array}$ & Test of significance & $P$ \\
\hline Age (years) & $40.96 \pm 8.94$ & $44.84 \pm 11.33$ & $42.80 \pm 13.83$ & $K=2.076$ & 0.354 \\
\hline \multicolumn{6}{|l|}{ Anthropometric measurements } \\
\hline Weight (kg) & $72.43 \pm 22.60$ & $77.18 \pm 13.92$ & $79.10 \pm 15.65$ & $K=2.491$ & 0.288 \\
\hline Height (cm) & $162.37 \pm 6.26$ & $162.12 \pm 8.06$ & $164.00 \pm 6.76$ & $K=0.476$ & 0.788 \\
\hline $\mathrm{BMI}\left(\mathrm{kg} / \mathrm{m}^{2}\right)$ & $27.36 \pm 8.18$ & $29.39 \pm 5.15$ & $26.40 \pm 6.60$ & $K=4.449$ & 0.108 \\
\hline \multicolumn{6}{|l|}{ BMI category } \\
\hline Underweight $^{\dagger}$ & $4(12.5)$ & $1(3.0)$ & $2(13.3)$ & $X^{2}=14.506$ & 0.069 \\
\hline Normal weight $^{\dagger}$ & $11(34.3)$ & $5(15.2)$ & $5(33.3)$ & & \\
\hline Overweight $^{\dagger}$ & $7(21.9)$ & $12(36.3)$ & $4(26.7)$ & & \\
\hline Obesity $^{\dagger}$ & $6(18.8)$ & $15(45.5)$ & $3(20.0)$ & & \\
\hline Morbid obesity $^{\dagger}$ & $4(12.5)$ & $0(0.0)$ & $1(6.7)$ & & \\
\hline Duration of symptoms (years) & $5.84 \pm 4.23$ & $3.84 \pm 1.85$ & NA & $Z=-1.748$ & 0.081 \\
\hline MODS & $13.06 \pm 5.16$ & $12.96 \pm 5.03$ & NA & $Z=-0.158$ & 0.875 \\
\hline Time of toileting (minutes) & $24.37 \pm 14.71$ & $20.75 \pm 9.27$ & NA & $Z=-0.756$ & 0.450 \\
\hline PAC-QOL & $42.34 \pm 14.64$ & $42.39 \pm 14.41$ & NA & $Z=-0.013$ & 0.990 \\
\hline Erectile function domain of IIEF & $18.71 \pm 3.32$ & $28.36 \pm 1.47$ & NA & $Z=-6.956$ & $\leq 0.0001^{*}$ \\
\hline \multicolumn{6}{|l|}{ Erectile function domain of IIEF interpretation } \\
\hline No ED ${ }^{\dagger}$ & $0(0)$ & $33(100)$ & NA & $x^{2}=65.000$ & $\leq 0.0001^{*}$ \\
\hline Mild $\mathrm{ED}^{\dagger}$ & $8(25.0)$ & $0(0)$ & NA & & \\
\hline Mild to moderate $\mathrm{ED}^{\dagger}$ & $13(40.6)$ & $0(0)$ & NA & & \\
\hline Moderate $\mathrm{ED}^{+}$ & $11(34.4)$ & $0(0)$ & NA & & \\
\hline Severe $\mathrm{ED}^{\dagger}$ & $0(0)$ & $0(0)$ & NA & & \\
\hline ED-EQoL & $44.25 \pm 10.09$ & NA & NA & NA & NA \\
\hline \multicolumn{6}{|l|}{ ED-EQoL interpretation } \\
\hline Mildly affected $\mathrm{QoL}^{\dagger}$ & $0(0)$ & NA & NA & NA & NA \\
\hline Moderately affected QoL ${ }^{\dagger}$ & $4(12.5)$ & NA & NA & NA & NA \\
\hline Severely affected $\mathrm{QoL}^{\dagger}$ & $28(87.5)$ & NA & NA & NA & NA \\
\hline \multicolumn{6}{|l|}{ Clinical and MRI findings } \\
\hline MOS $^{\ddagger}$ & $4(3-4)^{\|}$ & $4(3-5)^{\pi}$ & $5(5-0)^{\| \uparrow}$ & $K=42.160$ & $\leq 0.0001^{*}$ \\
\hline Rectocele $^{\dagger}$ & $14(43.8)$ & $13(39.4)$ & NA & $X^{2}=0.127$ & $0.804^{\S}$ \\
\hline Rectal intussusception ${ }^{\dagger}$ & $7(21.9)$ & $4(12.1)$ & NA & $X^{2}=1.099$ & $0.237^{\S}$ \\
\hline Increased perineal descent $^{\dagger}$ & $18(56.3)$ & $14(42.4)$ & NA & $X^{2}=1.242$ & $0.325^{\S}$ \\
\hline Anismus $^{\dagger}$ & $28(87.5)$ & $25(75.8)$ & NA & $X^{2}=1.488$ & $0.339^{\S}$ \\
\hline \multicolumn{6}{|l|}{ Type of OD } \\
\hline Functional $\mathrm{OD}^{+}$ & $13(40.6)$ & $18(54.5)$ & NA & $x^{2}=1.262$ & $0.324^{\S}$ \\
\hline Functional with mechanical $\mathrm{OD}^{\dagger}$ & $19(59.4)$ & $15(45.5)$ & NA & & \\
\hline $\begin{array}{l}\text { Hypoesthesia on the sensory territory of pudendal } \\
\text { nervet }\end{array}$ & $22(68.8)$ & $3(9.1)$ & NA & $x^{2}=24.430$ & $\leq 0.0001^{*}$ \\
\hline
\end{tabular}

Kg, kilogram; cm; centimeter; BMl, body mass index; kg/m², kilogram per meter square; MODS, modified obstructed defecation score; PAC-QoL, Patient assessment of Constipation-Quality of life questionnaire; IIEF, International Index of Erectile Function questionnaire; ED-EQoL, Erectile Dysfunction-Effect on Quality of Life questionnaire; MRI, dynamic pelvis magnetic resonance imaging; MOS, Modified Oxford Scale; OD, obstructed defecation; ED, erectile dysfunction; $\mathrm{n}$, number of subjects; SD, standard deviation; K, value of Kruskel-Wallis test; $X^{2}$, value of Chi-square test; $Z$, value of Mann Whitney test; NA, not applicable

* $P$ is significant at $<0.05$

${ }^{\dagger}$ Data are reported as number (percentage)

${ }^{\ddagger}$ Data are reported as median (range)

${ }^{\S}$ Value of Fisher's Exact test

\| Statistical significance difference between OD with ED group versus control group $(Z=-6.137, P \leq 0.0001)$

" Statistical significance difference between $O D$ without ED group versus control group $(Z=-5.405, P \leq 0.0001)$ 
Table 2 Anal manometric parameters of the two patient groups and control group

\begin{tabular}{|c|c|c|c|c|c|}
\hline Anal manometric parameters & $\begin{array}{l}\text { OD with ED group } \\
\text { ( } n=32 \text { patients) } \\
\text { mean } \pm S D\end{array}$ & $\begin{array}{l}\text { OD without ED group } \\
\text { ( } n=33 \text { patients }) \\
\text { mean } \pm S D\end{array}$ & $\begin{array}{l}\text { Control group } \\
\text { ( } n=15 \text { subjects) } \\
\text { mean } \pm \text { SD }\end{array}$ & Test of significance & $P$ \\
\hline Maximum squeezing anal pressure $(\mathrm{hPa})$ & $67.75 \pm 19.75^{\dagger}$ & $70.24 \pm 26.17^{\|}$ & $101.93 \pm 18.23^{\dagger \|}$ & $K=19.990$ & $\leq 0.0001^{*}$ \\
\hline Maximum straining anal pressure (hPa) & $57.93 \pm 13.34^{\neq 5}$ & $40.48 \pm 14.98^{ \pm}$ & $0 \pm 0^{\S}$ & $K=48.069$ & $\leq 0.0001^{*}$ \\
\hline
\end{tabular}

$\mathrm{hPa}$, hectopascal (it is the unit of pressure and it is equal to 100 Pascals); OD, obstructed defecation; ED, erectile dysfunction; $\mathrm{n}$, number of subjects; SD, standard deviation; K, value of Kruskel-Wallis test; $Z$, value of Mann Whitney test

${ }^{*} P$ is significant at $<0.05$

+ Statistical significance difference between OD with ED group versus control group $(Z=-4.373, P \leq 0.0001)$

₹ Statistical significance difference between OD with ED group versus OD without ED group $(Z=-4.189, P \leq 0.0001)$

${ }^{\S}$ Statistical significance difference between OD with ED group versus control group $(Z=-5.572, P \leq 0.0001)$

$\|$ Statistical significance difference between OD without ED group versus control group $(Z=-3.751, P \leq 0.0001)$

" Statistical significance difference between OD without ED group versus control group $(Z=-5.592, P \leq 0.0001)$

Table 3 Pelvic floor electrophysiological parameters of the two patient groups and control group

\begin{tabular}{|c|c|c|c|c|c|}
\hline $\begin{array}{l}\text { Pelvic floor electrophysiological } \\
\text { parameters }\end{array}$ & $\begin{array}{l}\text { OD with ED group } \\
\text { ( } n=32 \text { patients) } \\
\text { mean } \pm S D\end{array}$ & $\begin{array}{l}\text { OD without ED group } \\
(\mathrm{n}=33 \text { patients) } \\
\text { mean } \pm S D\end{array}$ & $\begin{array}{l}\text { Control group } \\
\text { ( } n=15 \text { subjects) } \\
\text { mean } \pm S D\end{array}$ & Test of significance & $P$ \\
\hline Rt PNTML (ms) & $3.67 \pm 1.39 \neq \S$ & $2.35 \pm 0.93 \ddagger^{\|}$ & $1.94 \pm 0.20 \S \|$ & $K=31.343$ & $\leq 0.0001^{*}$ \\
\hline LtPNTML (ms) & $3.19 \pm 1.18 \neq \S$ & $2.25 \pm 0.71 \neq^{\|}$ & $1.89 \pm 0.18 \S \|$ & $K=24.277$ & $\leq 0.0001^{*}$ \\
\hline \multicolumn{6}{|l|}{ Pudendal nerve status } \\
\hline Normal pudendal nerve bilaterally ${ }^{\dagger}$ & $4(12.5)$ & $15(45.45)$ & NA & \multirow[t]{5}{*}{$x^{2}=22.768$} & \multirow[t]{3}{*}{$\leq 0.0001^{*}$} \\
\hline Unilateral pudendal neuropathy ${ }^{\dagger}$ & $7(21.9)$ & $15(45.45)$ & NA & & \\
\hline Bilateral pudendal neuropathy ${ }^{\dagger}$ & $21(65.6)$ & $3(9.1)$ & NA & & \\
\hline \multicolumn{5}{|l|}{ Needle electromyography } & \\
\hline \multicolumn{5}{|l|}{ EMG of EAS } & \\
\hline Denervation with chronic reinnervation $^{\dagger}$ & $31(96.9)$ & $25(75.8)$ & NA & $X^{2}=6.073$ & $0.027 * \pi$ \\
\hline Anismus $^{\dagger}$ & $29(90.6)$ & $23(69.7)$ & NA & $X^{2}=4.447$ & $0.061^{\pi}$ \\
\hline \multicolumn{6}{|l|}{$E M G$ of $P R$} \\
\hline Denervation with chronic reinnervation $^{\dagger}$ & $23(71.9)$ & $19(57.6)$ & NA & $X^{2}=1.453$ & $0.301^{\natural}$ \\
\hline Anismus $^{\dagger}$ & $28(87.5)$ & $31(93.9)$ & NA & $X^{2}=0.804$ & $0.427^{\natural}$ \\
\hline \multicolumn{6}{|l|}{$E M G$ of $B C$} \\
\hline Denervation with chronic reinnervation $^{\dagger}$ & $25(78.1)$ & $11(33.3)$ & NA & $X^{2}=13.191$ & $\leq 0.0001^{* 9}$ \\
\hline
\end{tabular}

Rt, right side; PNTML, pudendal nerve terminal motor latency; Lt, left side; ms; millisecond; EMG, electromyography; EAS, external anal sphincter muscle; PR, puborectalis muscle; BC, bulbocavernosus muscle; $\mathrm{OD}$, obstructed defecation; ER, erectile dysfunction; n, number of subjects; SD, standard deviation; NA, not applicable; $\mathrm{K}$, value of Kruskel-Wallis test; $\mathrm{X}^{2}$, value of Chi-square test

${ }^{*} P$ is significant at $<0.05$

${ }^{\dagger}$ Data are reported as number (percentage)

* Statistical significance difference between OD with ED group versus OD without ED group $(P \leq 0.0001)$

$\S$ Statistical significance difference between OD with ED group versus control group $(P \leq 0.0001)$

" No statistical significance difference between OD without ED group versus control group $(P>0.05)$

"Value of Fisher's Exact test

parameters among OD with ED group of patients are tabulated in Table 4. There were statistical significant negative correlations between erectile function domain of IIEF questionnaire and time of toileting and PACQoL (Table 4). There was a statistically significant positive correlation between erectile function domain of IIEF questionnaire and maximum squeezing anal pressure (Table 4). There was a statistically significant negative correlation between ED-EQoL questionnaire and maximum squeezing anal pressure (Table 4).

Some co-variables were selected to be tested to assess their relation for the development of ED (Table 5). After adjusting the selected co-variables, the maximum straining anal pressure $(\mathrm{OR}=1.122)$, right PNTML $(\mathrm{OR}=3.755)$ and left PNTML $(\mathrm{OR}=3.770)$ were associated with significantly increasing the likelihood of 
Table 4 Correlation between erectile function domain of International Index of Erectile Function questionnaire and Erectile Dysfunction-Effect on Quality of Life questionnaire with different assessed parameters among patient group with erectile dysfunction ( $n=32$ patients)

\begin{tabular}{|c|c|c|c|c|}
\hline \multirow[t]{2}{*}{$\begin{array}{l}\text { Different clinical, } \\
\text { anal manometric and } \\
\text { electrophysiological parameters }\end{array}$} & \multicolumn{2}{|c|}{$\begin{array}{l}\text { Erectile } \\
\text { function } \\
\text { domain of IIEF } \\
\text { questionnaire }\end{array}$} & \multicolumn{2}{|c|}{$\begin{array}{l}\text { ED-EQoL } \\
\text { questionnaire }\end{array}$} \\
\hline & $r_{s}$ & $P$ & $r_{s}$ & $P$ \\
\hline Duration of symptoms (years) & 0.039 & 0.833 & 0.058 & 0.753 \\
\hline MODS & -0.344 & 0.054 & 0.103 & 0.576 \\
\hline Time of toileting (minutes) & -0.377 & $0.033^{*}$ & 0.138 & 0.452 \\
\hline PAC-QOL & -0.398 & $0.024^{*}$ & 0.275 & 0.127 \\
\hline \multicolumn{5}{|l|}{ Anal manometric parameters } \\
\hline $\begin{array}{l}\text { Maximum squeezing anal pressure } \\
(\mathrm{hPa})\end{array}$ & 0.546 & $0.001^{*}$ & -0.489 & $0.005^{*}$ \\
\hline $\begin{array}{l}\text { Maximum straining anal pressure } \\
(\mathrm{hPa})\end{array}$ & 0.076 & 0.678 & 0.119 & 0.516 \\
\hline \multicolumn{5}{|l|}{$\begin{array}{l}\text { Pelvic floor electrophysiological } \\
\text { parameters }\end{array}$} \\
\hline Rt PNTML (ms) & -0.372 & 0.051 & 0.303 & 0.118 \\
\hline LtPNTML (ms) & -0.202 & 0.303 & 0.241 & 0.217 \\
\hline
\end{tabular}

MODS, modified obstructed defecation score; PAC-QoL, Patient assessment of Constipation-Quality of life questionnaire; $\mathrm{hPa}$, hectopascal (it is the unit of pressure and it is equal to 100 Pascals); Rt, right side; PNTML, pudendal nerve terminal motor latency; ms, millisecond; Lt, left side; IIEF, International Index of Erectile Function questionnaire; ED-EQoL, Erectile Dysfunction-Effect on Quality of Life questionnaire; $r_{s}$, Spearman correlation coefficient

${ }^{*} P$ is significant at $<0.05$ development of ED (Table 5). Goodness of fit using the Hosmer and Lemeshow test was 11.563 with $P=0.172$. The OR of maximum straining anal pressure indicated that, when fixing all other selected co-variables constant, one-point increase in the maximum straining anal pressure is associated with the odds of developing ED by a multiplicative factor of 1.122 . The OR of PNTML (whether right side or left side) indicated that, when fixing all other selected co-variables constant, one-point increase in the PNTML is associated with the odds of developing ED by a multiplicative factor of 3.7.

\section{Discussion}

Erection is a physiological process. It depends on many vascular, hormonal, intra-corporal structure factors [7]. ED is the inability to attain and maintain an erection adequate and sufficient to allow satisfactory sexual performance [32]. It is a prevalent medical problem. It is present in about $52 \%$ of males between the 4 th and 7 th decade of life [33].

The pelvic floor muscles include the deep pelvic floor muscles and the superficial pelvic floor muscles. These superficial pelvic floor muscles include ischiocavernosus (IC) and $\mathrm{BC}$ muscles which have a role in erection [7]. The contraction of IC and BC muscles leads to penile erection by temporary increase in the corporeal body pressure [7]. Contraction of these two pairs of muscles performs compressive action necessary to increase intra-cavernous pressure. IC muscle contraction facilitates erection. $\mathrm{BC}$ muscle contraction slows the venous

Table 5 The results of logistic regression analysis predicting the development of erectile dysfunction from some selected assessed parameters among obstructed defecation patients $(n=65$ patients)

\begin{tabular}{|c|c|c|c|c|c|c|}
\hline \multirow[t]{2}{*}{ Selected co-variables } & \multirow[t]{2}{*}{$\beta$} & \multirow[t]{2}{*}{ Wald $\left(X^{2}\right)$} & \multirow[t]{2}{*}{ Odd ratio } & \multicolumn{2}{|l|}{$95 \% \mathrm{Cl}$} & \multirow[t]{2}{*}{$P$} \\
\hline & & & & Lower & Upper & \\
\hline Age (years) & -0.043 & 1.128 & 0.958 & 0.884 & 1.037 & 0.288 \\
\hline MODS & 0.017 & 0.026 & 1.017 & 0.827 & 1.252 & 0.872 \\
\hline Time of toileting (minutes) & 0.123 & 2.697 & 1.131 & 0.976 & 1.311 & 0.101 \\
\hline PAC-QoL & -0.146 & 3.770 & 0.864 & 0.746 & 1.001 & 0.052 \\
\hline Maximum squeezing anal pressure (hPa) & 0.017 & 0.485 & 1.017 & 0.970 & 1.065 & 0.486 \\
\hline Maximum straining anal pressure (hPa) & 0.115 & 5.917 & 1.122 & 1.023 & 1.231 & $0.015^{*}$ \\
\hline Rt PNTML (ms) & 1.323 & 4.459 & 3.755 & 1.100 & 12.822 & $0.035^{*}$ \\
\hline Lt PNTML (ms) & 1.327 & 3.964 & 3.770 & 1.021 & 13.926 & $0.046^{*}$ \\
\hline$x^{2+}$ & 11.563 & & & & & \\
\hline$P \neq$ & 0.172 & & & & & \\
\hline
\end{tabular}

MODS, modified obstructed defecation score; PAC-QoL, Patient assessment of Constipation-Quality of life questionnaire; hPa, hectopascal (it is the unit of pressure and it is equal to 100 Pascals); Rt, right side; PNTML, pudendal nerve terminal motor latency; ms, millisecond; Lt, left side; $\beta$, logistic regression standardized coefficients; Wald $\left(\mathrm{X}^{2}\right)$, Wald Chi-square test tests the unique contribution of each co-variable in relation to all other examined co-variables, through eliminating any overlap effect between them (i.e. when examining a co-variable, it holds all other co-variable constant); $\mathrm{Cl}$, confidence interval

*P is significant at $<0.05$

${ }^{\dagger}$ Value of Chi-square Hosmer and Lemeshow test

${ }^{\ddagger} P$ value of the Hosmer and Lemeshow test 
drainage from the corpora cavernosa through producing pressure on the deep dorsal vein of the penis [34]. These affect penile rigidity. Also, rhythmic $\mathrm{BC}$ muscles contraction propels the semen down the urethra producing ejaculation $[35,36]$.

These muscles are supplied by the perineal branch of pudendal nerve. Pudendal nerve is a branch arise from the sacral plexus. It leaves the pelvis through the inferior part of the greater sciatic foramen. It passes posterior to the ischial spine to reenter the pelvis through the superior part of the lesser sciatic foramen to enter the lateral wall of the ischio-rectal fossa. At the anterior end of the pudendal canal, it branches into the perineal nerve and the dorsal nerve of the penis. The perineal nerve supplies the IC and BC muscles [37].

There were $49.2 \%$ of the participated patients with OD had ED. This indicated that ED was a significant problem among OD patients. This should be taken into consideration when dealing with male OD patients. To the best of the authors' knowledge, this has not been previously reported in the literature.

The study was in accordance with previous studies regarding the presence of pudendal neuropathy among OD patients $[13,14,38,39]$. Pudendal neuropathy is a stretch neuropathy due to the long-standing stretching of the pudendal nerve with straining during defecation. Long-term straining during defecation results in subluxation and sagging of the levator ani muscles [16]. This leads to excessive perineal downward descent which stretches the pudendal nerve from the point of its fixation at the ischial spine $[13,14]$. Because the pudendal nerve winds around the ischial spine, the pudendal nerve is fixed at the ischial spine point and makes the distal part liable to stretch. It affects the distal part of the nerve that extends from the ischial spine to the pelvic floor muscles. Long-term stretching leads to neurapraxia that could be advanced to axonotmesis if stretch increased in severity [13]. This affects the function of all pudendal nerve supplied pelvic floor muscles including IC and $\mathrm{BC}$ muscles.

The percentage of patients with bilateral pudendal neuropathy was significantly higher among OD patients with ED. Pudendal neuropathy results in neurological changes in all pudendal nerve supplied muscles including EAS, IC and BC muscles [13, 14, 16, 17]. This explained the statistically significant difference between patients with ED versus those without ED regarding the percentage of patients with evidence of neuropathic abnormalities in the form of denervation and chronic reinnervation in the EAS and BC muscles. These neuropathic changes indicated that pudendal neuropathy had an essential role in the development of ED among OD patients. Regression analysis for some co-variables (Table 5) found that right PNTML $(\mathrm{OR}=3.755)$ and left PNTML $(\mathrm{OR}=3.770)$ were associated with significantly increasing the likelihood of development of ED. The OR of PNTML (whether the right side or the left side) indicated that, when fixing all other selected co-variables constant, one-point increase in the PNTML is associated with the odds of developing ED by a multiplicative factor of 3.7. These data were not previously assessed in the literature. In the situation that pudendal neuropathy led to ED, this could be considered a form of neurogenic impotence $[16,17,40]$.

Subsequently, OD patients with ED had a significantly lower MOS and maximum squeezing anal pressure. This could be due to the presence of stretch pudendal neuropathy which weakens the EAS muscle, as well as weakens other pudendal nerve innervated muscles including IC and $\mathrm{BC}$ muscles. $\mathrm{BC}$ muscle is considered an integral part of the EAS muscle $[41,42]$. It was reported that squeezing of EAS muscle is associated with $\mathrm{BC}$ muscle contraction [43]. Both BC and IC muscles share their contractile activity with the EAS [43-45]. The pelvic floor muscles are considered to form a single functional unit [7, 34]. Also, there is a concept that pathological changes in the EAS muscle (as the neuropathic changes presented in the present study) affect the erectile function with the development of ED. This concept is known as anocavernosal erectile dysfunction syndrome $[43,45]$.

The patients with ED had a significantly higher maximum straining anal pressure in comparison to those patients without ED. This indicated that the paradoxical contraction of the anal sphincter muscles in OD was more severe among those patients with ED. This led to more straining during defecation with more stretch pudendal neuropathy with subsequent the development of ED [13, 16]. Subsequently, regression analysis for some co-variables (Table 5) found that maximum straining anal pressure $(\mathrm{OR}=1.122)$ was associated with significantly increasing the likelihood of development of ED. The OR of maximum straining anal pressure indicated that, when fixing all other selected co-variables constant, one-point increase in the maximum straining anal pressure is associated with the odds of developing ED by a multiplicative factor of 1.122. This was not mentioned previously in the literature.

There was no statistically significant difference between patients with ED versus those without regarding the presence of neuropathic changes in the PR muscle. These neuropathic changes were due to the stretch neuropathy of the PR motor nerve supply which arises directly from the sacral plexus. This stretch could be due to the longstanding straining during defecation [46]. PR muscle has no role in the process of erection [7].

Anismus was present in EAS and PR muscles in a high percentage of patients. Anismus is the functional form of OD. This could be present as the only pathology in OD 
(i.e., functional OD) or associated with other anatomical structural abnormalities as rectocele. These were in accordance with previous studies [13, 29].

The statistically significant negative correlation between erectile function domain of IIEF questionnaire and the time of toileting could be an indication that the more the OD severity measured as the duration of time of toileting with straining during defecation associated with more pudendal neuropathy and subsequently poorer ED. This was not assessed previously in the literature.

The statistically significant negative correlation between erectile function domain of IIEF questionnaire and the PAC-QoL could be due to the impact of ED severity on the patient's QoL. Sexuality is considered a necessity for human well-being and abnormality in it affects the patient's overall QoL [47]. It was reported that ED affects the individual well-being and QoL [48, 49].

The statistically significant positive correlation between erectile function domain of IIEF questionnaire and the maximum squeezing anal pressure could be because the better pelvic floor muscles strength associated with better erectile function measured by IIEF. Also, the statistically significant negative correlation between ED-EQoL questionnaire and the maximum squeezing anal pressure could be because the better muscle strength of pelvic floor muscles associated with better erectile function with consequently the better the erectile function related QoL. The EAS muscle is the main responsible muscle for the generation of the maximum squeezing anal pressure. It forms a functional unit with other pelvic floor muscles including IC and BC muscles [7]. So, the poor function of the EAS muscle was associated with poor BC and IC muscles function manifested as ED. The BC and IC muscles assumed to be involved in different pathologies affecting the EAS muscle as in case of OD associated with pudendal neuropathy [43, 44, 50-52].

Pudendal neuropathy and maximum straining anal pressure were essential risk factors for the development of ED detected by regression analysis. In spite that these variables were not correlated significantly with erectile function domain of IIEF questionnaire, they were essential likelihood factors for the development of ED. These data were not reported previously in the literature.

The explanation that some patients with OD had no ED while others developed ED could be due to the following: (I) Excessive straining results in stretch of the inferior rectal branch of the pudendal nerve. This results in neuropathic changes in the EAS muscle. However, in severe and long-standing OD, excessive straining results in more severe pudendal neuropathy. This could affect all branches of the pudendal nerve including the perineal branch that supplies the IC and BC muscles with subsequently ED development. (II) From the anatomical and physiological point of view, the IC and BC muscles share their contractile activity with the EAS muscle. Consequently, the IC and $\mathrm{BC}$ muscles assumed to be involved in different pathologies affecting the EAS muscle $[43,44]$. So, the more involvement of the EAS muscle was associated with more involvement in the IC and $\mathrm{BC}$ muscles. (III) The consequences of OD are a wide spectrum of neuromuscular abnormalities that extends from mild condition to very severe condition in the form of severe bilateral pudendal neuropathy that results in ED and even fecal incontinence as a late complication $[13,14,53]$.

\section{Limitations of the work}

(i) Assessment of erectile function using the nocturnal penile tumescence assessment was not done [54]. This was in agreement with other researches [47]. Assessment of ED was done directly by subjective assessment questionnaire in the form of erectile function domain of IIEF questionnaire and indirectly by objective assessment of the maximum squeezing anal pressure which reflect the strength of contraction of EAS, as well as other pelvic floor muscles including IC and BC muscles [18, 20, 47].

(ii) The research did not evaluate pudendal somatosensory evoked potential. It is essential for diagnosis of patients with neurological disorders as central lesion (i.e., upper motor neuron lesion) and cauda equine lesions. However, patients with obvious neurological disorders were excluded from the study $[55,56]$.

(iii) BC reflex was not assessed. It was reported that the latency of the pelvic floor electrophysiological reflexes lacks sensitivity in detecting minimal to moderate grades of pudendal neuropathy. Also, they are not sensitive to detect incomplete nerve lesions (whether demyelinating or axonal neuropathy). This is because their assessment is based on conduction and not on compound muscle action potential amplitude [57]. The pelvic floor electrophysiological reflexes have a wide physiological range of latencies. When there is a minimal delay in their latency, it could still be within the accepted limit [53]. Consequently, when there is pelvic floor electrophysiological reflex within the normal range of latency, this does not exclude a lesion [14, 30, 55-57].

(iv) The limited number of included patients could be due to the wide range of exclusion criteria in the present study. Further studies on a larger scale of patients are recommended. 
This study is considered the first study that assessed the presence of ED among OD patients. Also, this study is considered the first study that assessed the relation between pelvic floor electrophysiological changes and ED among male OD patients. Early diagnosis of OD is essential for prevention of OD progression to more severe and more advanced stage that usually associated with more pudendal neuropathy with all its consequences as ED. Any physician dealing with a male patient with OD should be aware of the risk of development of ED. Enquiring about this issue is essential for proper diagnosis and treatment of OD and its consequences. The presence of severe and bilateral pudendal neuropathy associated with increased maximum straining anal pressure in a patient with OD should alert the treating physician for the risk of the presence of ED. This will encourage the role of pelvic floor rehabilitation for OD patients for early prevention, as well as for improvement of ED. This clinical problem could be treated by pelvic floor muscles exercises, as well as pelvic floor biofeedback therapy for improvement of the erectile function in association with improvement of OD [18, 47, 58].

The pelvic floor is considered a complex multifunctional unit which is essential for proper fecal continence and defecation; urinary continence and urination; and reproductive functions [7]. Pelvic floor muscle training helps in improving the strength of the pelvic floor muscles including the IC and $\mathrm{BC}$ muscles $[58,59]$. It is recommended that pelvic floor rehabilitation should start as early as possible for treatment of OD among male patients. It should be started early enough before the development of ED.

\section{Conclusions}

In conclusion, ED is prevalent among OD patients. It is associated with characteristic pelvic floor electrophysiological abnormalities in the form of bilateral pudendal neuropathy with neuropathic abnormalities in the EAS and $\mathrm{BC}$ muscles. Pelvic floor neurophysiological changes in OD vary from minimal to severe neuromuscular abnormalities that usually accompanying ED. Pudendal neuropathy and increased maximum straining anal pressure are essential risk factors for increasing the likelihood of development of ED in patients with OD.

\section{Abbreviations}

BC: Bulbocavernosus; EAS: External anal sphincter; ED: Erectile dysfunction; ED-EQoL: Erectile Dysfunction-Effect on Quality of Life Questionnaire; EMG:
Electromyography; IC: Ischiocavernosus; IIEF: International Index of Erectile Function; MODS: Modified Obstructed Defecation Score; MRI: Magnetic resonance imaging; QoL: Quality of life; PAC-QoL: Patient Assessment of Constipation-Quality of Life Questionnaire; PNTML: Pudendal nerve terminal motor latency; PR: Puborectalis; OD: Obstructed defecation; OR: Odd ratio; SD: Standard deviation.

\section{Acknowledgements}

The authors are grateful to Mariam Kamal Aziz Saba for her assistance in the statistical analysis. The authors are grateful to Maria Kamal Aziz Saba for her assistance in the preparation of the figures.

\section{Authors' contributions}

(MSE) contributed in the concepts, design, definition of intellectual content, clinical studies, data acquisition and manuscript revision. (EKAS) contributed in the concepts, design and definition of intellectual content, and did literature search, clinical studies, data acquisition and analysis, manuscript preparation, editing and revision. All the authors read and approved the manuscript.

\section{Funding}

The authors received no specific funding for this work. The authors declare that no financial or material support was provided by any parties and that there are no equity interests, patent rights or corporate affiliations for this work. This research did not receive any specific grant from funding agencies in the public, commercial, or not-for-profit sectors. There were no sponsors or funders (other than the named author) played any role in study design, data collection and analysis, decision to publish and preparation of the manuscript. All research facilities are available in our department for with no restrictions.

\section{Availability of data and materials}

The datasets used and/or analysed during the current study are available from the corresponding author on reasonable request.

\section{Declarations}

\section{Ethics approval and consent to participate}

The local Ethics Committee of Faculty of Medicine, Alexandria University, Egypt (IRB NO:00012098-FWA NO:00018699) approved the study. Date of approval:15/7/2019. Serial number: 0304356. A written informed consent was given by each

\section{Consent for publication}

Not applicable

\section{Competing interests}

The authors declare that they have no competing interests.

Received: 10 June 2021 Accepted: 6 August 2021

Published online: 22 September 2021

\section{References}

1. Pucciani F, Ringressi M (2012) Obstructed defecation: the role of anorectal manometry. Tech Coloproctol 16:67-72

2. Hoore A, Penninckx F (2003) Obstructed defecation. Colorectal Dis 5:280-287

3. Longstreth GF, Thompson WG, Chey WD, Houghton LA, Mearin F, Spiller RC (2006) Functional bowel disorders Gastroenterol 130:1480-1491

4. Spiller R, Thompson W (2010) Bowel disorders. Am J Gastroenterol 105:775-785

5. Andromanakos N, Skandalakis P, Troupis T, Filippou D (2006) Constipation of anorectal outlet obstruction: pathophysiology, evaluation and management. J Gastrol Hepatol 21:638-646 
6. Madbouly KM, Abbas KS, Saba EK (2017) Bilateral posterior tibial nerve stimulation in the treatment of rectal evacuation disorder: a preliminary report. Dis Colon Rectum 60:311-317

7. Pischedda A, Fusco F, Curreli A, Grimaldi G, Farina FP (2013) Pelvic floor and sexual male dysfunction. Arch Ital Urol Androl 85 (1):1-7

8. Kandeel FR, Koussa VK, Swerdloff RS (2001) Male sexual function and its disorders: physiology, pathophysiology, clinical investigation, and treatment. Endocr Rev 22:342-388

9. Cohen D, Gonzalez J, Goldstein I (2016) The role of pelvic floor muscles in male sexual dysfunction and pelvic pain. Sex Med Rev 4:53-62

10. MacDonagh R, Ewings P, Porter T (2002) The effect of erectile dysfunction on quality of life: psychometric testing of a new quality of life measure for patients with erectile dysfunction. J Urol 167 (1):212-217

11. Mestre M, Lleberia J, Pubill J, Espuña-Pons M (2015) Questionnaires in the assessment of sexual function in women with urinary incontinence and pelvic organ prolapse. Actas Urol Esp 39 (3):175-182

12. Caretta N, Foresta C (2007) Clinical diagnostic approach to erectile dysfunction. Minerva Ginecol 59:51-61

13. Saba EKA, El-Tantawi GAY, Zahran MH, Ibrahim KI, Shehata MA, Sultan HA et al (2015) Pelvic floor electrophysiology patterns associated with obstructed defecation [abstract]. Int J Med Health Sci 2 (7):118

14. Saba EKA, Elsawy MS (2019) Pelvic floor electrophysiological changes associated with female pelvic organ prolapse. World J Med Sci 16 (2):79-85

15. Antuna VC, Gomez JMF, Escaf S, Fernandez-Gonzalez F (2008) Neurogenic etiology in patients with erectile dysfunction. Arch Esp Urol 61:403-411

16. Shafik A (1994) Pudendal canal decompression in the treatment of erectile dysfunction. Arch Androl 32 (2):141-149

17. Naouar S, Braiek S, El Kamel R (2017) Erectile dysfunction secondary to pudendal nerve injury complicating orthopedic surgery: practical recommendations. J Curr Surg 7 (1-2):1-3

18. Al-Helow MR, Abdul-Hady H, Fathalla MM, Zakaria MA, Hussein O, El Gahndour T (2014) The role of biofeedback in the rehabilitation of venoocclusive erectile dysfunction. Egypt Rheumatol Rehabil 41:179-186

19. Drost J, Harris L (2006) Diagnosis and management of chronic constipation. J Am Acad Phys Assistants 19:24-30

20. Rosen RC, Cappelleri JC, Gendrano N (2002) The International Index of Erectile Function (IIEF): a state-of-the-science review. Int J Impot Res 14 (4):226-244

21. Hamdan FB, Al-Matubsi HY (2009) Assessment of erectile dysfunction in diabetic patients. Int J Androl 32:176-185

22. Agu AU, Esom EE, Anyaeji PS, Nzekwe KC, Chime SC, Ikele II et al (2019) Obesity indices and academic performance of medical students of Igbo extraction at College of Medicine, University of Nigeria. World J Med Sci $16(4): 191-195$

23. Sharma S, Agarwal BB (2012) Scoring systems in evaluation of constipation and obstructed defecation syndrome (ODS). J Int Med Sci Acad 25 (1):57-59

24. Bassotti G, Villanacci V (2013) A practical approach to diagnosis and management of functional constipation in adults. Intern Emerg Med 8 (4):275-282

25. Saba EKA, El-Tantawi GAY, Zahran MH, Ibrahim IK, Shehata MA, Sultan HA et al (2015) Evaluation of digital assessment of anal sphincter muscle strength [abstract]. Int J Med Health Scie 2 (9):122

26. Lang J, Brown H, Crombie E (2007) Assessment of the anal sphincter muscle: comparison of a digital and a manometric techniques. Physiotherapy 93:121-128

27. Gadel Hak N, El-hemaly M, Hamdy E (2011) Pelvic floor dyssynergia: efficacy of biofeedback training. Arab J Gastroenterol 12:15-19

28. Parry AH, Wani AH (2020) Evaluation of obstructed defecation syndrome (ODS) using magnetic resonance defecography (MRD). Egyptian Journal of Radiology and Nuclear Medicine 51:78 (https://doi.org/10.1186/ s43055-020-00197-z).

29. El-Shazly W, El-Nekady A, Hassan H (2010) Role of dynamic magnetic imaging in management of obstructed defecation case series. Int J Surg 8:274-282

30. Roberts M (2008) Neurophysiology in neurourology. Muscle Nerve 38:815-836
31. Lefaucheur JP (2006) Neurophysiological testing in anorectal disorders. Muscle Nerve 33:324-333

32. Lue TF, Giuliano F, Montorsi F, Rosen RC, Andersson KE, Althof S (2004) Summary of the recommendations on sexual dysfunctions in men. J Sex Med 1:6-23

33. Kligman EW (1991) Office evaluation of sexual function and complaints. Clin Geriatr Med 7:15-39

34. Rosenbaum TY (2007) Pelvic floor involvement in male and female sexual dysfunction and the role of pelvic floor rehabilitation in treatment: a literature review. I Sex Med 4:4-13

35. Dorey G (2000) Conservative treatment of erectile dysfunction. 2: Clinical trials, Br J Nurs 9 (12):755-762

36. Wespes E, Nogueira MC, Herbaut AG, Caufriez M, Schulman CC (1990) Role of the bulbocavernous muscles on the mechanism of human erection. Eur Urol 18:45-48

37. Thakar R, Fenner D (2009) Anatomy of the perineum and the anal sphincter. In: Sultan A, Thakar R, Fenner D (eds) Perineal and anal sphincter trauma: diagnosis and clinical management. Springer-Verlag, London, pp $1-12$

38. Vaccaro C, Cheong O, Wexner S, Nogueras J, Salanga V, Hanson M et al (1995) Pudendal neuropathy in evacuatory disorders. Dis Colon Rectum 38:166-171

39. Vaccaro C, Cheong O, Wexner S, Salanga V, Phillips R, Hanson M (1994) Role of pudendal nerve terminal motor latency assessment in constipated patients. Dis Colon Rectum 37:1250-1254

40. Jiinemann KP, Biihrle CP, Jiinemann CP (1994) Pathophysiology of neurogenic impotence. Sex Disabil 12 (1):5-16

41. Shafik A (1999) Physioanatomic entirety of external anal sphincter with bulbocavernosus muscle. Arch Androl 42 (1):45-54

42. Peikert K, Platzek I, Bessede T, May CA (2015) The male bulbospongiosus muscle and its relation to the external anal sphincter. J Urol 193:1433-1440

43. Shafik A, El-Sibai O (2000) The anocavernosal erectile dysfunction syndrome II Anal fissure and erectile dysfunction. Int J Impot Res 12:279-283

44. Shafik A, Shafik I, El-Sibai O, Shafik AA (2006) Effect of external anal sphincter contraction on the ischiocavernosus muscle and its suggested role in the sexual act. J Androl 27 (1):40-44

45. Shafik A (2001) Injured external anal sphincter in erectile dysfunction. Andrologia 33:35-41

46. Snooks S, Henry M, Swash M (1985) Anorectal incontinence and rectal prolapse: differential assessment of the innervation to puborectalis and external anal sphincter muscles. Gut 26:470-476

47. Mohammed AH, Zedan MA, Ban HM (2015) Role of pelvic floor muscle exercises in management of erectile dysfunction in patients with chronic obstructive pulmonary disease. Egypt J Chest Dis Tubercul 64:47-50

48. Burnett AL (2006) Erectile dysfunction. J Urol 175:S25-S31

49. Wagner G, Fugl-Meyer KS, Fugl-Meyer AR (2000) Impact of erectile dysfunction on quality of life: patient and partner perspectives. Int J Impot Res 12 (Suppl 4):S144-S146

50. Shafik A (1997) Pelvic floor muscles and sphincters during erection and ejaculation. Arch Androl 39 (1):71-78

51. Shafik A (1998) A new concept of the anatomy of the anal sphincter mechanism and the physiology of defecation: mass contraction of the pelvic floor muscles. Int Urogynecol J 9:28-32

52. Suriyut J, Muro S, Baramee P, Harada M, Akita K (2020) Various significant connections of the male pelvic floor muscles with special reference to the anal and urethral sphincter muscles. Anat Sci Int 95:305-312

53. Sultan HA, Zahran MH, Ibrahim IK, Shehata MA, El-Tantawi GA, Saba EK (2013) Pelvic floor electrophysiology patterns associated with faecal incontinence. Alex J Med 49:111-117

54. Elhanbly S, Elkholy A (2012) Nocturnal penile erections: the role of Rigiscan in the diagnosis of vascular erectile dysfunction. J Sex Med 9:3219-3226

55. Herman CW, Weinberg HJ, Brown J (1986) Testing for neurogenic impotence: a challenge. Urol 27 (4):318-231

56. Bianchi F, Squintani GM, Osio M, Morini A, Bana C, Ardolino G et al (2017) Neurophysiology of the pelvic floor in clinical practice: a systematic literature review. Funct Neurol 32 (4):173-193 
57. Fowler C (1995) Pelvic floor neurophysiology. In: Binnie C, Cooper R, Fowler C, Mauguiere F, Prior P (eds) Clinical neurophysiology: electromyography, nerve conduction and evoked potentials. Butterworth-Heinemann, Oxford, pp 233-252

58. Van Kampen M, De Weerdt W, Claes H, Feys H, De Maeyer M, Van Poppel $\mathrm{H}$ (2003) Treatment of erectile dysfunction by perineal exercise, electromyographic biofeedback, and electrical stimulation. Phys Ther 83 (6):536-543
59. Claes H, Baert L (1993) Pelvic floor exercise versus surgery in the treatment of impotence. Br J Urol 71:52-57

\section{Publisher's Note}

Springer Nature remains neutral with regard to jurisdictional claims in published maps and institutional affiliations.

\section{Submit your manuscript to a SpringerOpen ${ }^{\circ}$ journal and benefit from:}

- Convenient online submission

- Rigorous peer review

- Open access: articles freely available online

- High visibility within the field

- Retaining the copyright to your article

Submit your next manuscript at $\boldsymbol{\sim}$ springeropen.com 